\title{
Assessment of Magnetic Resonance Imaging Role in Diagnostic of Brain Infarction
}

\author{
Mohammed Mahjoub ${ }^{1,4}$, Mohamed Yousef ${ }^{2,3}$, Shazaly Khojaly ${ }^{3,4}$ \\ ${ }^{1}$ Alazhari University, Faculty of Radiological Sciences and Medical Imaging, Khartoum Sudan \\ ${ }^{2}$ Batterjee Medical College, Department of Radiological Science, Jeddah, Saudi Arabia \\ ${ }^{3}$ Sudan University for Sciences and Technology, College of Radiological Sciences, Khartoum, Sudan \\ ${ }^{4}$ Omdurman military hospital and modern medical center.,- Khartoum, Sudan
}

${ }^{5}$ Al-Ghad International College for Applied Medical Science, Medical Imaging Technology Department, Abha, KSA

\begin{abstract}
This study was carried out to assess the Magnetic Resonance Imaging (MRI) role in diagnosis of brain infarction among Sudanese at Khartoum, This study was done at Alzaiem Alazhari University-College of Graduate Studies and Omdurman military hospital and modern medical center, Khartoum, Sudan. This was a descriptive quantitative an observational cross-sectional study of 100 Sudanese patients admitting to all flowing hospitals for brain MRI scan, 50 female and male 50 their ages ranged between [18-80] years,. MRI studies were performed using 1.5 Tesla Toshiba whole body MRI machine. The results of this study revealed that the most common affected site of the lesions was left side, 5 patients [18-27] years, the mean size of brain infarction was [2.20 \pm 0.46$] \mathrm{mm}$. In 4 patients [28-37] years, the mean size was [3.30 \pm 0.35$] \mathrm{mm}$. In 14 patients [38-47] years, the mean size was [4.30 \pm 0.26$] .1 \mathrm{n} 19$ patients [48-57] years, the mean size was [5.36 \pm 0.32$] \mathrm{mm}$. In 29 patients [58-67] years the mean size was [6.24 \pm 0.30$] \mathrm{mm}$. In 20 patients [6877] years the mean size was [7.16 \pm 0.29$] \mathrm{mm}$. and in 4 patients [78-87] years, the mean size was [7.97 \pm 0.12$] \mathrm{mm}$. The present study concluded that there is a strong correlation between infarction size and age, as age increase the infarction size increase, the right side of the brain is more common site for infarction than the left one.. All four imaging sequence of MRI (T1, T2, FLAIR and DWI) have the same signal intensity for infarction appearance, the result of the study was in line with previous studies.
\end{abstract}

Keywords: MRI, Stroke, Perfusion, ischemic attack

\section{Introduction}

When Stroke is the third leading cause of death and the leading cause of permanent disability and disability adjusted loss of independent life-years in Western countries. ${ }^{1}$ Presently, the only specific, approved therapy for acute ischemic stroke is IV tissue plasminogen activator (tPA) given within 4.5 hours. $^{2-6}$. tPA use has been limited due to the short treatment window, concerns about the limitations of CT-based diagnosis, and fear of hemorrhagic risks.

Non contrast CT is the current diagnostic standard for acute stroke due to its wide availability and presumed near-perfect sensitivity for acute intracerebral hemorrhage (ICH) ${ }^{7,8}$. The most important differential diagnosis to ischemic stroke. For ischemic infarction, a number of early signs have been described $^{9}$, and formalized CT scores have been developed. ${ }^{10}$ The sensitivity of CT in acute ischemic stroke varies, depending on the imaging features of infarction, examination time from clinical onset, study population, and other variables.

Sensitivity estimates range from $12 \%$ to $92 \%$, with an overall estimate of $40 \%-60 \%$ for the 6-hour time window. ${ }^{11}$ A post hoc analysis of the CT data from the National Institute of Neurological Disorders and Stroke tPA study yielded a $31 \%$ sensitivity for early infarct signs. ${ }^{12}$

Despite the fact established by formal assessment of the evidence relative to an independent standard, CT has become the de facto diagnostic standard.

As non-contrast CT has limited sensitivity for the diagnosis of ischemic stroke in the initial hours, improved accuracy of stroke diagnosis is necessary for the development and application of optimal thrombolytic and other stroke therapy. ${ }^{12,13}$ New MRI techniques such as diffusion-weighted imaging (DWI).

And perfusion-weighted imaging (PWI) add another dimension to diagnostic imaging ${ }^{14,15}$ and have the potential to improve the diagnostic yield while being practical and feasible.

DWI measures the net movement of water in tissue due to random (Brownian) molecular motion of water and shows hyper intense ischemic tissue changes within minutes to a few hours after arterial occlusion due to a reduction of the apparent

Diffusion coefficient (ADC). ${ }^{16,17}$. The ADC reduction occurs primarily in the intracellular space associated with disruption in membrane ionic homeostasis

And cytotoxic edema. Decreases in the ADC and increased signal on DWI studies in many instances represent irreversible ischemia. To differentiate acute from subacute or older lesions (T2 shine-through), DWI is used in conjunction with T2-weighted images and ADC maps. 


\section{International Journal of Science and Research (IJSR) \\ ISSN (Online): 2319-7064 \\ Index Copernicus Value (2015): 78.96 | Impact Factor (2015): 6.391}

PWI allows the measurement of capillary perfusion. The method most commonly used in clinical practice and research is the dynamic susceptibility contrast-enhanced technique, in which paramagnetic contrast agent is injected as an IV bolus and the signal change is tracked by susceptibility-weighted, T2*-weighted magnetic resonance (MR) sequences. ${ }^{18}$ Relative cerebrovascular hemodynamic measures reflecting cerebral blood volume, mean transit time, time to peak, and cerebral blood flow (CBF) can be derived from the MR signal intensity-over-time curve in a semi quantitative fashion. Parameter maps display the area of critically reduced perfusion.

Although studies have overcome the usual logistical obstacles to the emergency use of MRI, ${ }^{19,20}$

As there is no true imaging gold standard for acute ischemic stroke that has been established by comparison with neuropathologic findings, ${ }^{21}$ the reference diagnosis of ischemic stroke in most MRI studies is established using a follow-up lesion on CT or conventional MR images consistent with the clinical syndrome and a comprehensive diagnostic workup.

The brain injuries caused by strokes are a major cause of adult disability in the United States. Someone has a stroke every 53 seconds. Someone dies of a stroke every 3 minutes. Older people are most at risk of having strokes, although they can happen at any age including in children and stroke is more common in men than in women ${ }^{22}$.

A CT scan or MRI of the head is typically the first test performed. MRI (Magnetic resonance imaging) is a test that uses a magnetic field and pulses of radio wave energy to make pictures of organs and structures inside the body. In many cases, MRI gives different information about structures in the body than can be seen with an X-ray, ultrasound, or computed tomography scan. MRI also may show problems that cannot be seen with other imaging methods. Magnetic resonance imaging device offers stunning images of the brain, spine, and soft tissues located around joints ${ }^{23}$.

Diffusion-weighted magnetic resonance imaging provides image contrast that is different from that provided by conventional magnetic resonance techniques. It is particularly sensitive for detection of acute ischemic stroke and differentiation of acute stroke from other processes that manifest with sudden neurologic deficits. Because stroke is common and in the differential diagnosis of most acute neurologic events, diffusion-weighted magnetic resonance imaging should be considered an essential sequence, and its use in most brain magnetic resonance studies is recommended ${ }^{24}$.

\section{Material and Method}

This was a descriptive quantitative an observational crosssectional study of 100 Sudanese patients admitting to all flowing hospitals for brain MRI scan , 50 female and male 50 their ages ranged between [18-80] years.
The study was conducted at Khartoum state in Magnetic Resonance Imaging (MRI) department of Omdurman military hospital and modern medical center in the period from April 2016 until April 2017.

Inclusion criteria: Any patient with brain infarction.

Exclusion criteria of the study cases: Patients with normal finding or other brain abnormalities.

Study variables include (Age, Sex, Clinical history, Magnetic Resonance Imaging (MRI) findings

Data was collected using data collection sheet and analyzed using SPSS (Statistical package for Social Sciences).

Magnetic Resonance Imaging (MRI) machine 1.5 Tesla Toshiba made in Japan

\section{MRI Techniques:}

Coil used: head coil

Sequence: sagittal T1 / axial T2, flair T2, axial T1, Diffusion weighted image DWI

Patient was in supine position and Metal object were removed (e.g. coin and keys) prior imaging.

All of images were interpreted by radiologist .

\section{Result Presentation}

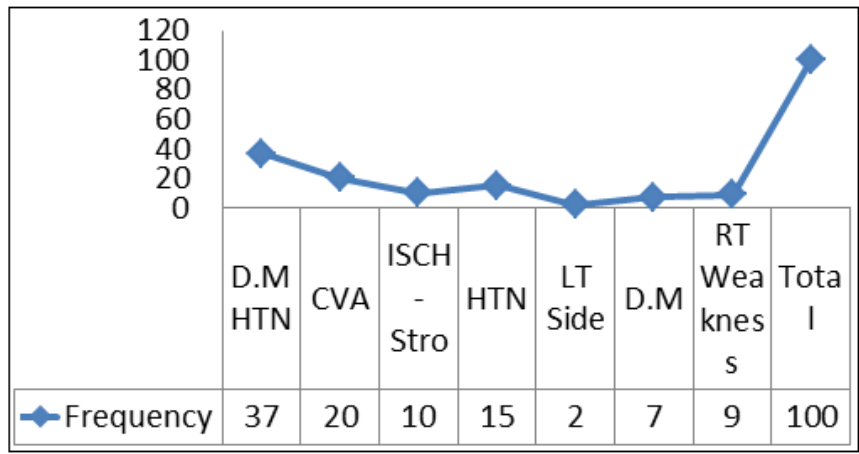

Figure 1: Show frequency distribution for Clinical History among all patients load current (amperes)

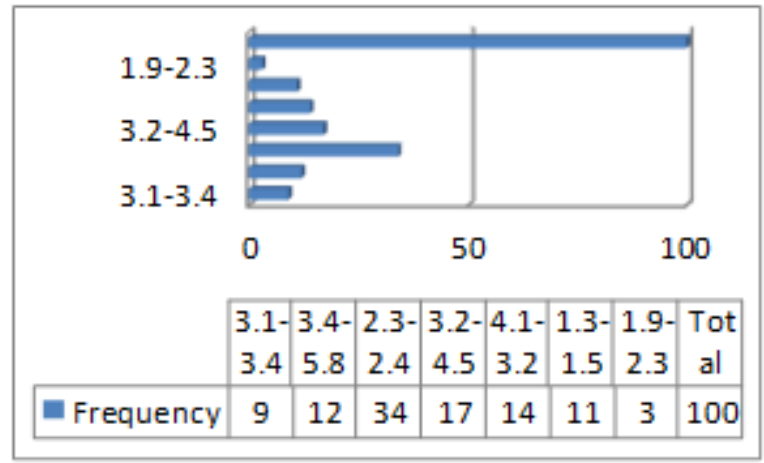

Figure 2: Figure 4.3 show frequency distribution of Size T1 for all patients 


\section{International Journal of Science and Research (IJSR) \\ ISSN (Online): 2319-7064}

Index Copernicus Value (2015): 78.96 | Impact Factor (2015): 6.391

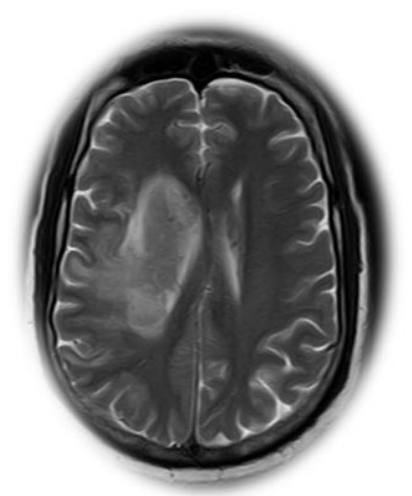

Figure 3: Shows MRI Brain of 57 Years m Female

C/O: Left side weakness revealed Large right capsular area showing mixed low and high signals, surrounding by oedema is contend consistent with acute haemorrhagic infract.The infarct compresses the body of right lateral ventricle and causes midline shift to left side.

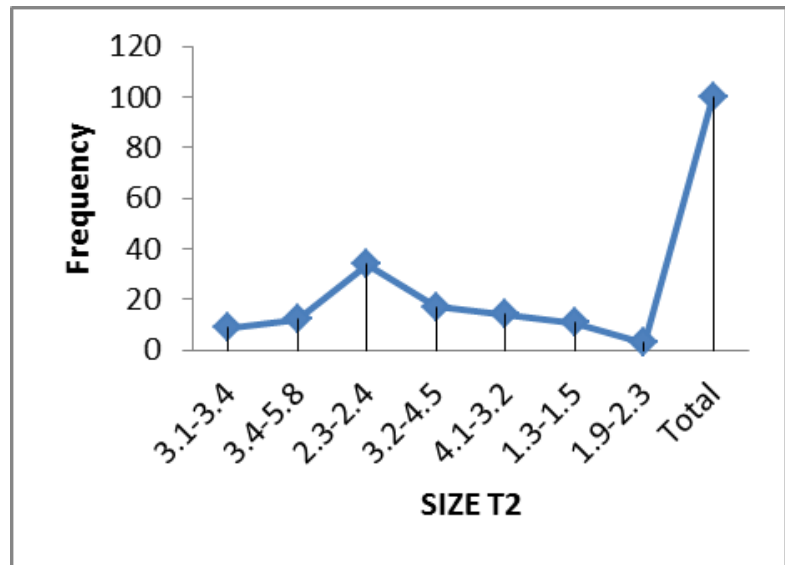

Figure 4: Shows frequency distribution of Size T2 for all patients

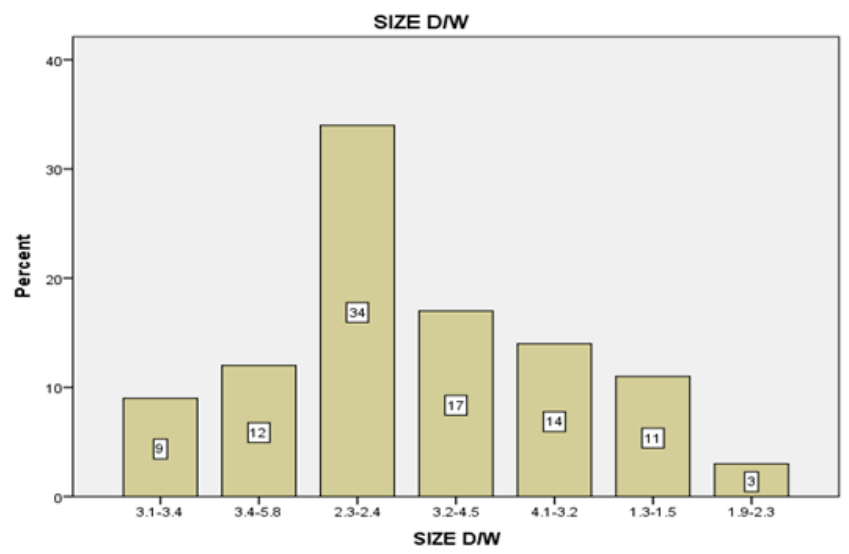

Figure 5: Shows frequency distribution of Size D/W for all patients

Table 1: Shows frequency distribution of age group

\begin{tabular}{|c|c|}
\hline Age Group & Frequency \\
\hline $18-27$ & 5 \\
\hline $28-37$ & 4 \\
\hline $38-47$ & 14 \\
\hline $48-57$ & 19 \\
\hline $58-67$ & 29 \\
\hline $68-77$ & 20 \\
\hline $78-87$ & 4 \\
\hline
\end{tabular}

Table 2: Shows distribution of size vs. age group

\begin{tabular}{|c|c|c|}
\hline Age Group & Mean & SD \\
\hline $18-27$ & 2.2 & 0.46 \\
\hline $28-37$ & 3.3 & 0.35 \\
\hline $38-47$ & 4.3 & 0.26 \\
\hline $48-57$ & 5.36 & 0.32 \\
\hline $58-67$ & 6.24 & 0.30 \\
\hline $68-77$ & 7.16 & 0.29 \\
\hline $78-87$ & 7.97 & 0.12 \\
\hline
\end{tabular}

\section{Discussion}

This study was carried out to assess the Magnetic Resonance Imaging (MRI) role in diagnosis of brain infarction among Sudanese at Khartoum, This study was done at AlzaiemAlazhari University-College of Graduate Studies and Omdurman military hospital and modern medical center, Khartoum, Sudan. This was a descriptive quantitative an observational cross-sectional study of 100 Sudanese patients admitting to all flowing hospitals for brain MRI scan , 50 female and male 50 their ages ranged between [18-80] years, MRI studies were performed using 1.5 Tesla Toshiba whole body MRI machine. The results of this study revealed that the most common affected age group included 29 patients [5867] years with mean size was [6.24 \pm 0.30$] \mathrm{mm}$. There is a strong correlation between infarction size and age, as age increase the infarction size increase, the right side of the brain is more common site for infarction than the left ..All four imaging sequence of MRI (T1, T2, FLAIR and DWI) have the same signal intensity for infarction appearance, the result of the study was in line with previous studies From these results there is a correlation between infarction size and age, as age increase the infarction size increase. Finding of this study agree with finding of the study done by Sanak D, et $\mathrm{al}^{25}$ and Abdelaziz I et al ${ }^{26}$

\section{Conclusion}

This study concluded that Magnetic Resonance Imaging (MRI) allows accurate diagnosis of the infarct lesion with any signal intensity imaging.

Magnetic Resonance Imaging (MRI) allows accurate diagnosis of the infarct lesion, detection of cerebral arterial occlusion or significant stenosis with evaluation of actual collateral flow and may also display certain reversible ischemic changes.

Cerebral infarctions are more frequent in older patients, so the clinical positive case should be referred for MRI. From the study there is a strong correlation between infarction size and age, as age increase the infarction size increase. Further studies are needed to confirm the results acquired with this study for brain infarctions with more data collections.

\section{References}

[1] Lloyd-Jones D, Adams R, Carnethon M, et al. Heart disease and stroke statistics: 2009 update: a report from the American Heart Association statistics committee and 


\section{International Journal of Science and Research (IJSR) \\ ISSN (Online): 2319-7064}

Index Copernicus Value (2015): 78.96 | Impact Factor (2015): 6.391

stroke statistics subcommittee. Circulation 2009; 119:e21-e181.

[2] Easton D, Saver JL, Albers GW, et al. Definition and evaluation of transient ischemic attack: a scientific statement for healthcare professionals from the American Heart Association/ American Stroke Association Stroke Council. Stroke 2009;40:2276 2293.

[3] Adams HP Jr, del Zoppo G, Alberts MJ, et al. Guidelines for the early management of adults with ischemic stroke: a guideline from the American Heart Association/American Stroke Association Stroke Council. Stroke 2007;38:1655-1711.

[4] The National Institute of Neurological Disorders and Stroke rt-PA Stroke Study Group. Tissue plasminogen activator for acute ischemic stroke. N Engl J Med 1995;333: 1581-1587.

[5] Hacke W, Kaste M, Bluhmki E, et al. Thrombolysis with alteplase 3 to 4.5 hours after acute ischemic stroke. N Engl J Med 2008;359:1317-1329.

[6] del Zoppo GJ, Saver JL, Jauch EC, et al. Expansion of the time window for treatment of acute ischemic stroke with intravenous tissue plasminogen activator: a science advisory from the American Heart Association/American Stroke Association. Stroke 2009;40:2945-2948.

[7] Fiebach JB, Schellinger PD, Gass A, et al. Stroke magnetic resonance imaging is accurate in hyperacute intracerebral hemorrhage: a multicenter study on the validity of stroke imaging. Stroke 2004;35:502-507.

[8] Kidwell CS, Chalela JA, Saver JL, et al. Comparison of MRI and CT for detection of acute intracerebral hemorrhage. JAMA 2004;292:1823-1830.

[9] von Kummer R, Allen KL, Holle R, et al. Acute stroke: usefulness of early CT findings before thrombolytic therapy. Radiology 1997;205:327-333.

[10] Barber PA, Demchuk AM, Zhang J, Buchan AM. Validity and reliability of a quantitative computed tomography score in predicting outcome of hyperacute stroke before thrombolytic therapy: ASPECTS Study Group Alberta Stroke Programme Early CT Score. Lancet 2000;355: 1670-1674.

[11] von Kummer R, Bozzao L, Manelfe C, eds. Early CT Diagnosis of Hemispheric Brain Infarction, 1st ed. Berlin: Springer Verlag; 1995.

[12] Patel SC, Levine SR, Tilley BC, et al. Lack of clinical significance of early ischemic changes on computed tomography in acute stroke. JAMA 2001;286:2830 2838.

[13] Fiebach JB, Schellinger PD, Jansen O, et al. CT and diffusion-weighted MR imaging in randomized order: diffusion-weighted imaging results in higher accuracy and lower interrater variability in the diagnosis of hyperacute ischemic stroke. Stroke 2002;33:2206 -2210.

[14] Schellinger PD, Fiebach JB, Hacke W. Imaging-based decision making in thrombolytic therapy for ischemic stroke: present status. Stroke 2003;34:575-583.

[15] Warach S. Stroke neuroimaging. Stroke 2003;34:345347.

[16] Liu Y, Laakso MP, Karonen JO, et al. Apolipoprotein E polymorphism and acute ischemic stroke: a diffusionand perfusion-weighted magnetic resonance imaging study. J Cereb Blood Flow Metab 2002;22:1336 -1342.
[17] Moseley ME, Cohen Y, Mintorovitch J, et al. Early detection of regional cerebral ischemia in cats: comparison of diffusion- and T2-weighted MRI and spectroscopy. Magn Reson Med 1990;14:330 -346.

[18] Rosen BR, Belliveau JW, Vevea JM, Brady TJ. Perfusion imaging with NMR contrast agents. Magn Reson Med 1990;14:249 -265.

[19] Buckley BT, Wainwright A, Meagher T, Briley D. Audit of a policy of magnetic resonance imaging with diffusionweighted imaging as first-line neuroimaging for in-patients with clinically suspected acute stroke. Clin Radiol 2003; 58:234-237.

[20] Schellinger PD, Jansen O, Fiebach JB, et al. Feasibility and practicality of MR imaging of stroke in the management of hyperacute cerebral ischemia. AJNR Am J Neuroradiol 2000;21:1184 -1189.

[21] von Kummer R. Imaging of stroke pathology without predefined gold standard. Cerebrovasc Dis 2002;14:270; author reply 271 .

[22] Miniño, Arialdi, Jiaquan $\mathrm{Xu}$, and Kenneth Kochanek, 2010, Deaths: Preliminary Data for 2008. National Vital Statistics Reports (2010) 59.

[23] Chalela JA, Kidwell CS, Nentwich LM, 2007, Magnetic resonance imaging and computed tomography in emergency assessment of patients with suspected acute stroke: a prospective comparison. Lancet;369:293e8

[24] Keir S, Wardlaw JM, Bastin ME, 2004, In which patients is diffusion-weighted magnetic resonance imaging most useful in routine stroke care? J Neuroimaging; 14:118e22.

[25] Sanak D, Horak D, Herzig R, Hlustik P, Kanovsky P., The role of magnetic resonance imaging for acute ischemic stroke. Biomed Pap Med Fac Univ Palacky Olomouc Czech Repub. 2009 Sep;153(3):181-7.

[26]Ikhlas Abdelaziz, Hussein Hassan, Salah Ali, Mohammed Yousef, Kalid Abdelmoneim, Duha Abdo, Muna Ahamed, Hassan A Hamed, Evaluation of MRI Protocol for Acute Stroke, INDIAN JOURNAL OF APPLIED RESEARCH, Volume : 6 | Issue : 11 | November 2016

\section{Author Profile}

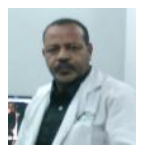

Mr. Mohammed Abdel Lateef Al-Khalifa (Sudan) received the B.Sc. degree in diagnostic radiology technology, Alzaiem Alazhari University, 1999, he was working as radiology technologist, in radiology department in military hospital now he is working as radiology head department in Alia specialized hospital Omdurman , and he has been active in MRI and diagnostic radiology researches Inc.

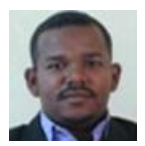

Mr. Shazaly Nader Khojaly Mansour (Sudan) received (B.Sc.) in diagnostic radiology technology and (M.Sc.) in medical ultrasound imaging from College of Medical radiological Science, Sudan University of Science and Technology in 2011 and 2015 respectively. Now as lecturer at AlGhad international college for medical sciences, Medical imaging technology department, KSA ,Abha from 2016 up to now.

\section{Volume 6 Issue 7, July 2017 www.ijsr.net}

